DOI: $10.1002 /$ smll.201701808

Article type: Full paper

\title{
Memantine Loaded PEGylated Biodegradable Nanoparticles for the Treatment of Glaucoma
}

E. Sánchez-López ${ }^{1,2}$, M.A. Egea ${ }^{1}$, B.M Davis ${ }^{3}$, L. Guo $^{3}$, M. Espina ${ }^{1}$, A. M. Silva ${ }^{4}$, A.C.

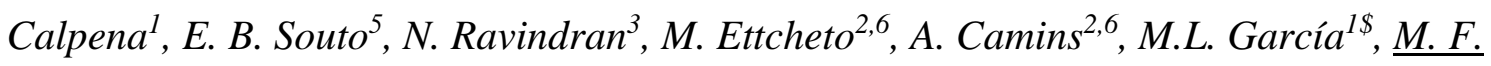
$\underline{\text { Cordeiro }}^{3,7 \$^{*}}$

${ }^{1}$ Department of Pharmacy, Pharmaceutical Technology and Physical Chemistry, Faculty of Pharmacy, University of Barcelona. Institute of Nanoscience and Nanotechnology (IN2UB).

2 Biomedical Research and Networking Center in Neurodegenerative diseases (CIBERNED), Madrid, Spain

${ }^{3}$ Glaucoma and Retinal Neurodegeneration Research, Visual Neuroscience, UCL Institute of Ophthalmology, Bath Street, London EC1V 9EL, UK

${ }^{4}$ Department of Biology and Environment, School of Life and Environmental sciences (ECVA, UTAD), and Centre for Research and Technology of Agro-Environmental and Biological Sciences (CITAB-UTAD), University of Trás-os-Montes e Alto Douro, Quinta de Prados, 5001-801 Vila Real, Portugal.

5 Department of Pharmaceutical Technology, Faculty of Pharmacy, University of Coimbra (FFUC) and REQUIMTE/Group of Pharmaceutical Technology, Polo das Ciências da Saúde, Azinhaga de Santa Comba, 3000-548 Coimbra, Portugal

${ }^{6}$ Department of Pharmacology and Pharmaceutical Technology, Faculty of Pharmacy, University of Barcelona

${ }^{7}$ Western Eye Hospital, Imperial College Healthcare Trust, London, UK

\$Senior co-authors

E-mail: $\underline{\text { m.cordeiro@ucl.ac.uk }}$

$\mathrm{PhD}$ and MD M. F. Cordeiro

UCL Institute of Ophthalmology

Bath Street, London EC1V 9EL, UK 


\section{WILEY-VCH}

Keywords: nanoparticles, PLGA-PEG, Memantine, drug delivery, glaucoma

\section{Abstract}

Glaucoma is a multifactorial neurodegenerative disease associated with RGC loss. Increasing reports of similarities in glaucoma and other neurodegenerative conditions, have led to speculation that therapies for brain neurodegenerative disorders may also have potential as glaucoma therapies. Memantine is an NMDA antagonist approved for Alzheimer's disease treatment. Glutamate-induced excitotoxicity is implicated in glaucoma and NMDA receptor antagonism has been advocated as a potential strategy for RGC preservation. This study describes the development of a topical formulation of memantine loaded PLGA-PEG nanoparticles (MEM-NP) and investigates the efficacy of this formulation using a well-established glaucoma model. Nanoparticles were characterized by dynamic light scattering and ${ }^{1} \mathrm{H}-\mathrm{NMR}$, confirming the nanoparticle character $(<200 \mathrm{~nm})$ and high drug incorporation $(4 \mathrm{mg} / \mathrm{mL}$ of which $0.35 \mathrm{mg} / \mathrm{mL}$ was localized within the aqueous interior). In vitro assessment indicates an element of sustained release and ex vivo corneal and scleral permeation studies demonstrate that incorporation into a nanoparticle enhanced memantine delivery. Moreover, MEM-NP was shown to be well-tolerated in human retinoblastoma cells and in vivo (Draize test). MEM-NP eye drops were applied daily for three weeks to a rodent model of ocular hypertension. MEM-NP were found to significantly ( $p<0.0001)$ reduce RGC loss. These results suggest that topical MEM-NP is safe, well-tolerated and most promisingly, neuroprotective in an experimental glaucoma model. 


\section{WILEY-VCH}

\section{Introduction}

Glaucoma is a multifactorial neurodegenerative disease and the second leading cause of vision loss worldwide. ${ }^{[1]}$ Although the exact mechanism of glaucoma pathology is debatable, ${ }^{[2,3]}$ the disease induces damage to optic nerve axons thus resulting in progressive loss of retinal ganglion cells (RGC). Elevated intraocular pressure presently remains the only clinically modifiable risk factor for glaucoma and, therefore, traditional therapeutic strategies seek to reduce elevated intraocular pressure (IOP). However, there are patients who suffer glaucoma and vision loss with normotensive IOP values. ${ }^{[4]}$ Although it has been shown that there is some improvement in the course of the disease in normotensive glaucoma (NTG) patients by lowering the IOP, there is growing recognition that IOP reduction alone is not adequate in some patients who continue to lose vision despite well-controlled IOPs. ${ }^{[4,5]}$ As a result, there has been widespread research on IOP-independent neuroprotective strategies ${ }^{[6]}$ for glaucoma patients. ${ }^{[7]}$ Increasingly, there has been a recognition that similar mechanisms of cell death occur in glaucoma and Alzheimer's disease (AD), including dysregulation of neurotrophic growth factors, caspase activation, and glutamate excitotoxicity. ${ }^{[8]}$ Therapies advocated in AD have also been suggested for glaucoma. One such treatment is the NMDA (N-methyl-Daspartate) receptor antagonists Memantine (MEM). ${ }^{[9]}$

MEM is a neuroprotective agent approved by the FDA for the treatment of AD that acts by inhibiting NMDA-induced glutamate excitotoxicity; it may also prevent RGC death in glaucoma. ${ }^{[5]}$ Although preclinical data previously suggested a potential clinical benefit of orally administered MEM for the treatment of glaucoma, ${ }^{[10]}$ the efficacy of this route of MEM administration is limited, and may have contributed to the results of a phase III clinical trial in glaucoma which apparently failed in meeting its primary endpoint. ${ }^{[1,12]}$ 


\section{WILEY-VCH}

A key challenge for MEM in glaucoma is the development of a safe and effective means of long-lasting delivery of MEM to the back of the eye. ${ }^{[13]}$ Incorporation of MEM into a nanoparticle drug delivery systems could provide a strategy to enhance the efficacy of this agent by increasing concentrations in target retinal tissues whilst reducing the risk of side-effects associated with systemic dosing regimens. ${ }^{[14]}$ Nanocarriers have also been shown to enable loaded drug molecules to penetrate to posterior ocular tissues by promoting drug delivery across anterior ocular barriers including the lipidic tear film and corneal epithelial barrier and increasing drug residency time after eye drop instillation. ${ }^{[15-}$ ${ }^{17]}$ Poly(lactic-co-glycolic acid) or PLGA is presently the most widely used biocompatible and biodegradable polymer in the field of nanocarrier systems. It is FDA approved and is reported safe for the delivery of ophthalmic agents. ${ }^{[18]}$ Moreover, polymeric PLGA nanoparticles (NPs) have been reported to facilitate the sustained delivery of other existing IOP-lowering agents to intraocular tissues. ${ }^{[17]}$ Previously, PLGA has been covalently attached to hydrophilic polymers such as polyethylene glycol (PEG) due to its hydrophilicity and biocompatibility. This was found to enhance nanoparticle mucoadhesion by increasing residency time on the ocular surface. ${ }^{[19]}$

In this study, we sought to develop a novel biodegradable PLGA-PEG nanoparticle formulation of MEM which could be applied as an eye-drop once a day. Topical administration is favored over subtenon or intravitreal implants owing to noninvasiveness, reduced risk of side-effects, ability to self-administer and inherent socioeconomic costs. ${ }^{[13,20]}$ Encapsulation of MEM in MEM-PLGA-PEG NPs was achieved using a double emulsion method. Stability, in vitro and ex vivo release of the constructed nanosystems were determined prior to assessing the neuroprotective activity of optimized formulations in a well-established rodent model of ocular hypertension. 


\section{Results}

\subsection{Preparation of a homogeneous nanoparticle suspension of PLGA-PEG- memantine using the double emulsion method}

MEM-NP were developed using a double emulsion method using ethyl acetate as the organic solvent due to its partial water solubility and reduced toxicity compared to dichloromethane (class III and II, respectively according to ICH specifications). ${ }^{[21]}$ Design of experiments (DoE) was used to obtain a suitable formulation for eye delivery studying the modifications of $\mathrm{pH}$ and composition of the two aqueous phases ( $\mathrm{w}_{1}$ and $\left.\mathrm{w}_{2}\right)$. As shown in Figure 1A, smaller MEM-NP average size $\left(\mathrm{Z}_{\mathrm{av}}\right)$ were obtained as the $\mathrm{pH}$ of the $\mathrm{w}_{1}$ phase was similar to drug $\mathrm{pK}_{\mathrm{a}}(10.7)$. A reduction in polydispersity index (PI) was also observed by maintaining $\mathrm{w}_{1}$ under alkaline conditions thus favouring MEM-NP homogeneity (Figure 1B). Encapsulation efficiency (EE) was also found to be maximal $\left(80.6 \%\right.$ ) at $\mathrm{w}_{1} \mathrm{pH} 11$ and $\mathrm{w}_{2} \mathrm{pH} 6.5$ (Figure $1 \mathrm{C}$ ). EE values $\sim 80 \%$ were obtained with a $4.5 \mathrm{pH}$ difference between the two phases, meaning the nanoparticles incorporated 4 $\mathrm{mg} / \mathrm{mL}$ of memantine and this formulation was used in subsequent experiments (F6, Table 1).

Optimized MEM-NP were found to have a mean diameter $<200 \mathrm{~nm}$ after centrifugation, a PI suggesting formulation homogeneity $(0.078 \pm 0.018)$, characteristic of the monodisperse systems $(\mathrm{PI}<0.1)$ and a sufficiently negative zeta potential $(\mathrm{ZP})$ to suggest the NP dispersion may be stable in solution $(-26.5 \mathrm{mV}$, the negative charge increased after

centrifugation due to PVA removal). Using dynamic light scattering, ${ }^{[22]}$ particles were found to be monodisperse, with a mean diameter of $141.8 \mathrm{~nm}$, (Suppl. Figure 1A\&B). Results were supported by transmission electron microscopy (TEM) observations, the structure of MEM NPs was distinct from the structure of crystalline memantine (Figure 


\section{WILEY-VCH}

2A \& B). MEM-NP were found to be spherical and well dispersed with a mean diameter of $78.51 \mathrm{~nm} \pm 11.01 \mathrm{~nm}$ (supplementary material Figure 3C). AFM results supported this observation with smooth spherical NPs with a mean horizontal and vertical distance of $89.8 \mathrm{~nm}$ and $98.08 \mathrm{~nm}$ respectively (Figure 2C \&D). Differential scanning calorimetry (DSC) thermograms are shown in Figure 3A \& B. The exotermic peak observed during the cooling process of the sample correspond to MEM NP freezing temperature. The freezing onset is $-15.99{ }^{\circ} \mathrm{C}$ and after freezing and heated MEM NP showed a glass transition temperature $\left(\mathrm{T}_{\mathrm{g}}\right)$ endotermic peak at $9.69^{\circ} \mathrm{C}$. Furthermore, MEM NP and empty NP were compared without the cooling process. The thermograms of MEM NP showed that the $\mathrm{T}_{\mathrm{g}}\left(56.39{ }^{\circ} \mathrm{C}\right)$ is slightly increased compared with empty $\mathrm{NP}\left(52.85{ }^{\circ} \mathrm{C}\right)$. The proton nuclear magnetic resonance $\left({ }^{1} \mathrm{H}-\mathrm{NMR}\right)$ profile of MEM-NPs, empty nanoparticles and empty nanoparticles spiked with memantine are shown in Figure $3 \mathrm{C}$. Here, $\mathrm{D}_{2} \mathrm{O}$ was used as a solvent, with a reference peak $(\delta=0)$ from the methyl signal of trimethylsilyl propanoic acid (TMSP). ${ }^{[23]}$ Compared to MEM-NP, or empty nanoparticles characteristic memantine peaks were observed in MEM-NP spectra $(2.2,1.4$ and $0.9 \mathrm{ppm}) .{ }^{[24]}$ The profile of empty nanoparticles is comparable to that previously reported in the literature, with characteristic peaks around $4 \mathrm{ppm}$ and $1.7 \mathrm{ppm}$ corresponding to the $\mathrm{CH}$ of lactic acid and methylene groups of the glycol and methyl groups of the lactic acid respectively. ${ }^{[25,26]}$ As is shown in Figure 3B, one of the striking features is a large peak at 3.7 ppm due to the methylene groups of the MePEG. ${ }^{[22,23]}$ Traces of ethyl acetate were observed in the sample, with peaks at $4.1 \mathrm{ppm}$ and 1.24 corresponding to the ethyl quadruplet and methyl triplet of $\mathrm{CH}_{2} \mathrm{CH}_{3}$ respectively, however these were insufficient to cause ocular irritation. $^{[23]}$

\subsection{PLGA-PEG nanocarriers encapsulate memantine and demonstrate an element}

\section{of sustained release}




\section{WILEY-VCH}

The backscattering profile for MEM-NPs maintained at $25^{\circ} \mathrm{C}$ for $24 \mathrm{~h}$ is shown in Figure 4. Except for peripheral peaks at the vial edges, a constant signal around $38 \%$ could be observed throughout the study without variations higher than $10 \%$ thus indicating good short-term stability of the formulation. ${ }^{[28]}$ In vitro release of memantine fit well $\left(\mathrm{R}^{2}=\right.$ 0.976) to a single phase exponential association equation (eq. 1) liberating all memantine within $4 \mathrm{~h}$ with a half-life of $0.74 \mathrm{~h}$ (Figure 5). To assess the proportion of memantine that had been incorporated into the aqueous interior of the double emulsion compared to the surrounding hydrophobic (oil phase) milieu in vitro release from MEM-NPs was fit to a one- (eq. 1) or two-phase exponential association equation (eq. 1 and 2 respectively ${ }^{[29]}$ ) constraining the fast half-life as that for free memantine.

$$
\begin{array}{r}
\mathrm{Y}=\mathrm{Y} 0+(\mathrm{P}-\mathrm{Y} 0) *\left(1-\exp \left(-\mathrm{K}^{*} \mathrm{x}\right)\right) \\
\mathrm{S}_{\mathrm{F}}=\left(\mathrm{P}-\mathrm{Y}_{0}\right) * \mathrm{~F} * .01 \\
\mathrm{~S}_{\mathrm{s}}=\left(\mathrm{P}-\mathrm{Y}_{0}\right) *(100-\mathrm{F}) * .01 \\
\mathrm{Y}=\mathrm{Y}_{0}+\mathrm{S}_{\mathrm{F}} *\left(1-\exp \left(-\mathrm{K}_{\mathrm{F}} * \mathrm{X}\right)\right)+\mathrm{S}_{\mathrm{S}} *\left(1-\exp \left(-\mathrm{K}_{\mathrm{S}} * \mathrm{X}\right)\right)
\end{array}
$$

where $\mathrm{Y}_{0}$ and $\mathrm{P}$ are the starting and final values of $\%$ memantine release (fixed as $0 \%$ and $100 \%$ respectively) and $\mathrm{K}$ is the rate constant in units reciprocal of the $\mathrm{y}$ axis. In equation $2, S_{F}$ and $S_{\mathrm{s}}$ describe the span of the fast and slow component respectively, $K_{F}$ and $K_{S}$ describe the rate of the fast and slow component respectively and $\mathrm{F}$ describes the percentage of signal due to the fast phase.

The best fitting model was determined to be eq. 2 using an extra sum of squares F-test ( $F$ $=45.41, \mathrm{p}<0.0001)$, with a slow half-life of $6.0 \mathrm{~h}\left(\mathrm{R}^{2}=0.9828\right)$. This result suggests a portion of the memantine contained within MEM-NPs has been successfully incorporated 


\section{WILEY-VCH}

into the aqueous interior of the double emulsion. Using (eq.2) the proportion of memantine in this slow release fraction was estimated to be $8.68 \%$ which equates to $0.35 \mathrm{mg} / \mathrm{mL}$ of the total incorporated memantine. As free memantine in solution was removed from MEM-NPs prior to conducting this assay, the fast release fraction is likely to be memantine rapidly liberated from the nanoparticle oil phase. This may explain why the greatest encapsulation of memantine was achieved at the $\mathrm{pK}$ of this drug where it has no overall charge and at its most lipophilic.

\section{Ex vivo corneal and scleral permeation studies}

Ex vivo corneal and scleral permeation studies were carried out up to $6 \mathrm{~h}$ (Figure 5B \& C). MEM-NP depicted a slower drug release on scleral tissue than on the cornea. The slope for corneal permeation was $6.64 \pm 0.17 \mu \mathrm{g} \cdot \mathrm{cm}^{2} \cdot \mathrm{h}^{-1}$ whereas the slope for scleral permeation was $0.23 \pm 0.01 \mu \mathrm{g} \cdot \mathrm{cm}^{2} \cdot \mathrm{h}^{-1}$. Lag time $\left(\mathrm{T}_{\mathrm{L}}\right)$ was almost null in both tissues, suggesting that MEM-NPs achieve the steady-state in the ocular tissue within a few minutes after its application. ${ }^{[30]}$ The permeability coefficient $\left(\mathrm{K}_{\mathrm{p}}\right)$ was $0.01 \mathrm{~cm} / \mathrm{h}$ for cornea and $2.79 \cdot 10^{-4} \mathrm{~cm} / \mathrm{h}$ for scleral. On both cases, the parameter was highly influenced by $\mathrm{P}_{2}\left(\mathrm{~K}_{\mathrm{p}}=\mathrm{P}_{1} \cdot \mathrm{P}_{2}\right) . \mathrm{P}_{2}$ corresponds to the partition coefficient inside both tissues although, as demonstrated in previous publications, PLGA-PEG NP show significant corneal tropism, with a suggestion that memantine could be released slowly from within the cornea. ${ }^{[31]}$ In addition, free drug retention in corneal tissue was $0.01 \mu \mathrm{g} / \mathrm{mg}$ whereas in sclera it was 10 fold higher $(0.11 \mu \mathrm{g} / \mathrm{mg})$.

\subsection{In vitro cytotoxicity and in vivo ocular tolerance assessment}

In order to assess the safety of the produced MEM-NP, cell viability studies were carried out using retinoblastoma (Y-79) and keratinocytes (HaCaT) cells. As can be observed in Figure $6 \mathrm{~A}, \mathrm{MEM}-\mathrm{NP}$ at 24 or $48 \mathrm{~h}$ of exposure did not cause a reduction in cell viability, 


\section{WILEY-VCH}

whereas free memantine was found to be cytotoxic at $50 \mu \mathrm{M}$ after $48 \mathrm{~h}(\mathrm{p}<0.001)$ but not $24 \mathrm{~h}$ of cell contact. The free drug also showed toxicity in retinoblastoma cells after shortterm exposure (Figure 6B). These differences in exposure time and toxicity in different cell lines might be due to differences in cell metabolism. In contrast to the free drug, MEM-NP did not show toxicity in any of the assessed concentrations, with cell viability values greater than $80 \%$, possibly related to the polymeric matrix slowing memantine release and reducing cell exposure to cytotoxic concentrations.

In vitro ocular tolerance was assessed using the Hen's egg test chorioallantoic membrane (HET-CAM). ${ }^{[32]}$ Addition of $0.9 \%$ saline solution to healthy membranes was used as a negative control which produced no adverse effects after five minutes. In contrast, application of a severe irritant (1 M sodium hydroxide) induced immediate and severe haemorrhages, which served as a positive control (Figure 7A). The application of $0.3 \mathrm{~mL}$ of free memantine onto the chorioallantoic membrane, induced small haemorrhages (Figure 7B) suggestive of mild irritation. In contrast instillation of the same volume and concentration of MEM-NPs was found to be well-tolerated and induced no detectable irritation (Figure 7C \& D). ${ }^{[33]}$ Upon completion of these in vitro tests, a tolerance assay was conducted in male albino rabbits. Similar to the in vitro result, MEM-NP had a low OII and were therefore classified as non-irritant, whereas administration of free memantine was found to induce a degree of inflammation, and was therefore classified as slightly irritant.

\subsection{MEM-NPs are neuroprotective in a rodent model of ocular hypertension}

After unilateral induction of the Morrison's ocular hypertension model in Dark Agouti (DA) rats, two drops of MEM-NP were administered daily for three weeks. Peak IOP was observed 1 day after surgery, and IOP elevation was sustained for at least 7 days (Figure 


\section{WILEY-VCH}

8A). The IOP profile was comparable between MEM-NP and OHT control groups (20.59 $\pm 3.81 \mathrm{mmHg}$ and $19.81 \pm 0.93 \mathrm{mmHg}$ respectively) suggesting that MEM-NP therapy did not affect IOP.

Surviving RGC were visualised histologically in retinal flat mounts using the RGC specific nuclear-localized transcription factor Brn3a (Figure 8B). Quantification of RGC populations was completed using an automated script as previously described. ${ }^{[34]}$ Global RGC density was significantly diminished in the untreated OHT group versus naïve controls $(p<0.001$, Figure 8A). Treatment with MEM-NP was found to significantly protect against OHT induced RGC injury in this model $(p<0.001)$, suggesting it was neuroprotective in a non-IOP-dependent manner.

\section{Discussion}

In the present work, we developed a novel MEM-NP formulation using DoE in conjunction with a double emulsion method. MEM-NPs were found to be homogeneous with an average diameter $<200 \mathrm{~nm}(141.8 \mathrm{~nm})$ with high drug loading $(4 \mathrm{mg} / \mathrm{mL})$. Incorporated memantine was found to be localised at the particle surface and interior using in vitro release assays. As a single parameter cannot be used to adequately describe the sample distribution, ${ }^{[35]}$ sub $200 \mathrm{~nm}$ particle size and spherical shape was confirmed using DLS, TEM and AFM investigations, suggesting this formulation would be unlikely

to cause ocular irritation. ${ }^{[36]}$ MEM NP were found to be well tolerated using a number of established in vitro and in vivo assays and these results suggest that topical MEM-NP is safe and well-tolerated formulation with neuroprotective activity in a well-established experimental model of glaucoma. 


\section{WILEY-VCH}

The MEM-NP formulation comprised a PLGA-PEG polymeric matrix which was synthesized using a modified double emulsion method. This technique was used due to its suitability for the encapsulation of hydrophilic compounds, minimising the escape of these molecules from the aqueous core so increasing formulation stability, one of the main drawbacks of hydrophilic drug loading into liposomes. ${ }^{[21]}$ The greatest memantine encapsulation efficiency was observed using $\mathrm{pH}$ values of w1 similar to memantine $\mathrm{pKa}$ (10.7, ChemAxon). A possible explanation for this observation is that memantine is most hydrophobic at its $\mathrm{pK}$, maximizing solubility in the nanoparticle oil phase. This suggestion is supported by subsequent in vitro release assays which estimate that of the 4 $\mathrm{mg} / \mathrm{mL}$ memantine incorporated into the formulation, $0.35 \mathrm{mg} / \mathrm{mL}$ was released slowly from nanoparticles (suggestive of encapsulation within the aqueous interior), while 3.65 $\mathrm{mg} / \mathrm{mL}$ was released at a similar rate to free memantine. As unencapsulated memantine was removed from the formulation prior to in vitro assessment, we propose that the more rapidly released fraction was instead liberated from the lipophilic nanoparticle component. As a result, while $4 \mathrm{mg} / \mathrm{mL}$ of drug was incorporated into the formulation, $0.35 \mathrm{mg} / \mathrm{mL}$ of this material was incorporated within the aqueous nanoparticle core (the slower release fraction) and this may be the more relevant value to compare with other formulations. After confirming the release profile of the MEM-NPs, sclera and cornea of rabbits were used to investigate the permeation of formulated memantine across intraocular barriers. MEM-NP corneal penetration was found to be higher than scleral permeation but, interestingly, the amount of memantine found within scleral tissue could suggest that administration of MEM-NPs results in the formation of a drug reservoir in the sclera from which memantine diffuses into intraocular tissues. 


\section{WILEY-VCH}

DSC results supported encapsulation of MEM as a result of the increase in $\mathrm{T}_{\mathrm{g}}$ observed on drug entrapment. The increasing of the $\mathrm{T}_{\mathrm{g}}$ of the polymer could be attributed to the incorporation of an alkaline drug, which causes interactions between the carboxylic groups of the polymer. In addition, results suggest that this formulation will be amenable to freeze-dried. ${ }^{[37]}$ In vitro cell viability studies were performed demonstrating that MEMNPs were better tolerated than free memantine by epithelial and neuronal cultures. Results from HET-CAM irritation tests were in agreement with in vitro observations, confirming not only the sensitivity of the in vitro test but also the non-irritant properties of the developed formulation and suitability for ocular administration. ${ }^{[29,32]}$ These results are in accordance with those obtained by other groups working with PLGA-NPs for ocular applications. ${ }^{[33,34]}$ We anticipate that encapsulation of memantine within the NP aqueous interior acts to slow memantine release and therefore reduces cell exposure to potentially cytotoxic concentrations of this agent.

Having established the tolerability of MEM-NPs, the neuroprotective effect of this formulation on RGC health was next assessed using an established in vivo rodent model of ocular hypertension. Quantitative assessment of RGC loss after three weeks of ocular hypertension induction was assessed using Brn3a immunofluorescence in conjunction with a previously described automatic image segmentation script. ${ }^{[34]}$ Brn3a is a nuclearrestricted POU-domain family transcription factor expressed exclusively by RGCs (97\% of the total RGC population) in the rat retina which plays a role in differentiation, survival and axonal elongation during development, thus providing an indirect indication of the functional state of the RGC. ${ }^{[41]}$ As such, Brn3a several authors have previously used this marker to quantify RGC density in several rodent and mammalian glaucoma models. ${ }^{[41,42]}$ Twice-daily topical administration of MEM-NPs for three weeks was found to significantly protect RGC soma from injury in this model in an IOP independent manner, 


\section{WILEY-VCH}

suggestive of a neuroprotective effect. Although several animal models of glaucoma have been described, it is important to remember that they are imperfect and do not presently recreate all aspects of the human condition. ${ }^{[35,36]}$ Despite this limitation, models such as the Morrison's ocular hypertension model used in this paper reproduce some aspects of the glaucoma, namely RGC loss in response to IOP elevation as the extent of IOP correlates with RGC loss and damage of RGC axons in untreated OHT eyes. ${ }^{[46]}$

RGC loss in the rodent model of ocular hypertension is reported to occur via a combination of primary and secondary degenerative processes. ${ }^{[34]}$ Where, primary degeneration of RGCs occurs as a result of injury and secondary degeneration describes the loss of RGCs as a consequence of the primary insult, for example as a result of oxidative stress, inflammation or excitotoxicity. ${ }^{[47]}$ Glutamate excitotoxicity has previously been reported to play a role in RGC loss in the OHT model. ${ }^{[48]}$ An attractive explanation for the neuroprotective effect of topically administered memantine nanoparticles in the OHT model could therefore be due to the well documented NMDA receptor antagonism of this agent. ${ }^{[49]}$

In addition to its effect on glutamate excitotoxicity, there are more recent reports that memantine can also lower amyloid beta peptide levels in vitro and in a transgenic murine model of AD.$^{[50-52]}$ Recent work by Ito et al suggests that the mechanism of memantine mediated reduction in amyloid beta is independent of $\alpha, \beta$ or $\gamma$-secretase activity and instead influences amyloid precursor protein (APP) trafficking. Here, reduction of APP endocytosis results in the accumulation of a greater proportion of cellular APP at the plasma membrane where it is predominantly processed via the non-amyloidogenic pathway so reducing amyloid beta production. ${ }^{[52]}$ This is significant as there is growing evidence for the involvement of amyloid beta accumulation in glaucoma pathology ${ }^{[53-55]}$ 


\section{WILEY-VCH}

and increasing recognition of mechanistic similarities between these neurodegenerative disorders. ${ }^{[50,51]}$ In further support of this hypothesis, we recently demonstrated brimonidine-mediated RGC neuroprotection (an $\alpha 2$-adrenergic receptor agonist) in the OHT model were mediated in part by a reduction in amyloid beta production and promotion of the non-amyloidogenic pathway. ${ }^{[55]}$ Finally, as multiple studies now also link the progression of age-related macular degeneration (AMD) with amyloid beta accumulation, ${ }^{[58]}$ non-amyloidogenic promoting therapies such as brimonidine and memantine may also provide useful therapies for the treatment of AMD.

Orally administered memantine has previously been tested in a Phase III clinical trial the treatment of primary open-angle glaucoma, however, the trial was reported to have failed to meet its primary endpoints. ${ }^{[11]}$ To date, several hypotheses have been proposed to explain the reasons for its failure, including; study endpoints that lacked sufficient power to identify a smaller but therapeutically relevant effect and insufficient treatment periods. ${ }^{[11]}$ Owing to these study limitations and despite a high-profile failure, the use of non-competitive NMDA antagonists for the treatment of glaucoma remains a promising therapeutic avenue for the development of novel glaucoma therapies. ${ }^{[59]}$

While some authors postulate that the use of more potent NMDA receptor antagonists such as bis(7)-tacrine may overcome the perceived limitations associated with the use of memantine for the treatment of glaucoma, ${ }^{[11]}$ we postulate that by instead developing approaches to increase the concentration of memantine delivered to intraocular tissues via its incorporation into nanoparticles for local administration could provide an alternative strategy to achieve this goal. 


\section{WILEY-VCH}

To date, the majority of the preclinical studies examining memantine for the treatment of glaucoma, intraperitoneal, ${ }^{[54,55]}$ subcutaneous, ${ }^{[62]}$ or oral ${ }^{[63]}$ administration routes were investigated. For studies involving oral administration in monkeys, doses of between 2 and $8 \mathrm{mg} / \mathrm{kg}$.day are reported, ${ }^{[64]}$ while Alzheimer's disease patients are currently prescribed between 10 and $20 \mathrm{mg} /$ day. The local administration of memantine permitted by our nanoparticle formulation resulted in localised dosing of approximately 0.125 $\mathrm{mg} / \mathrm{rat} / \mathrm{day}$. This reduced dosing in combination with localised administration would likely reduce the risk of systemic adverse effects associated with memantine therapy ${ }^{[65]}$ while ensuring the delivery of therapeutically relevant concentrations of the drug to target tissues.

In this study, we demonstrated a novel PLGA-PEG nanocarrier for the delivery of therapeutically relevant concentrations to posterior ocular tissues using a rodent model of ocular hypertension. The biodegradable and mucoadhesive properties of PLGA-PEG nanoparticles are well-documented and likely promoted memantine delivery to intraocular tissues through increasing pre-corneal drug residence. ${ }^{[19]}$ Other groups have previously formulated memantine into nanoparticles. Prieto and colleagues developed Gantrez, a memantine-loaded poly(anhydride) nanoparticle formulation which possessed a similar diameter as our formulation but only contained $0.055 \mathrm{mg}$ of memantine per $\mathrm{mg}$ of nanoparticles. ${ }^{[13]}$ While the authors demonstrated sustained release of memantine from these formulations after sub-tenon and intravitreal injection in the rabbit, the authors did not investigate topical administration. While these results are of interest, invasive intraocular therapeutic administration is less desirable than non-invasive topical administration route. ${ }^{[6]}$ More recently, lipoyl-memantine loaded solid lipid nanoparticles $^{[67]}$ and memantine-pamonic acid nanocrystalline salts ${ }^{[68]}$ have been 


\section{WILEY-VCH}

described. Each of these formulations exhibited a sub-200 nm size and good homogeneity but only solubilized $\sim 0.1 \mathrm{mg} / \mathrm{mL}$ of lipoyl-memantine and $0.028 \mathrm{mg} / \mathrm{mL}$ of memantinepamonic acid respectively. To the authors' knowledge, neither of these formulations have been assessed as a glaucoma therapy.

\section{Conclusion}

This study describes a novel PLGA-PEG nanoparticle formulation that that incorporates $4 \mathrm{mg} / \mathrm{mL}$ of memantine with an $80 \%$ encapsulation efficiency of which $0.35 \mathrm{mg} / \mathrm{mL}$ was contained within the particles within the nanoparticle aqueous interior . This formulation was found to be better-tolerated than free-memantine by epithelial and neuronal cell cultures in vitro and was found to be neuroprotective through significant preservation of RGC density in a well-established rodent ocular hypertension model of glaucoma after twice-daily topical in vivo. In summary, we propose topical administration of memantine loaded nanoparticles as a novel technique as a safe, non-invasive and effective strategy for the treatment of glaucoma.

\section{Experimental section}

MEM-NP preparation. MEM-NP were prepared by a modification of the double emulsion solvent evaporation technique. ${ }^{[69]}$ Briefly, 100 mg of PLGA-PEG was dissolved in $2 \mathrm{ml}$ of ethyl acetate. $25 \mathrm{mg}$ of memantine was dissolved into $1 \mathrm{ml}$ of water at $\mathrm{pH}$ 11. Primary emulsion $\left(\mathrm{w}_{1} / \mathrm{o}\right)$ was obtained by applying ultrasound energy with an ultrasonic probe for 30s (38\% of amplitude). $2 \mathrm{ml}$ of PVA at $23 \mathrm{mg} / \mathrm{mL}$ was added and ultrasound was applied for 3 minutes. Finally, $2 \mathrm{ml}$ of PVA $0.3 \%$ was added dropwise under magnetic stirring and the $\mathrm{w}_{1} / \mathrm{o} / \mathrm{w}_{2}$ emulsion was stirred overnight to evaporate the organic solvent. 


\section{WILEY-VCH}

Characterization of MEM-NP. MEM-NP $\mathrm{Z}_{\mathrm{av}}$ and PI were determined by photon correlation spectroscopy (PCS) with a Zetasizer Nano ZS (Malvern Instruments, Malvern, $\mathrm{UK}$ ) at $25^{\circ} \mathrm{C} \cdot{ }^{[39]} \mathrm{ZP}$ was evaluated by laser-doppler electrophoresis with M3 PALS system. In all the determinations, the samples were diluted with MilliQ water (1:10). Results represent mean $\pm \mathrm{SD}, \mathrm{N} \geq 3$.

EE was determined indirectly using a Triple Quadrupole LC/MS/MS Mass Spectrometer (Perkin-Elmer Sciex Instruments). Prior to analysis, free drug was separated from nanoparticles by filtration using an Ultra 0.5 centrifugal filter device (Amicon Millipore Corporation, Ireland). EE was calculated using equation (3);

$$
\mathrm{EE}(\%)=\frac{\text { Total amount of } M E M-\text { Free } M E M}{\text { Total amount of } M E M}
$$

Memantine quantification was performed in multiple reaction monitoring (MRM) mode of an ion-trap MS equipped with an atmospheric pressure electrospray ionization ion source and an Agilent 1100 series HPLC system (Agilent Technologies, USA) coupled with a Brucker Ion Trap SL (Brucker Daltonics GmbH, Germany). memantine was separated on a reversed phase column (Kinetex de $2.6 \mu \mathrm{m} 50$ x 2.1 (Phenomenex) using methanol $0.1 \%$ formic acid in water 55:45 (v/v) as mobile phase. The flow rate was 1 $\mathrm{ml} / \mathrm{min}$ at $45^{\circ} \mathrm{C} \cdot{ }^{[70]}$

Preparation of MEM-NP using a DoE approach. MEM-NP formulation was optimized by investigating the influence of $\mathrm{pH}$ on NP size, dispersity, ZP and EE (Table 1). The effect of a factor (Ex) was calculated according to equation (4):

$$
\mathrm{Ex}=\frac{\sum_{x}(+)-\sum_{x}(-)}{n / 2}
$$




\section{WILEY-VCH}

Where $\Sigma_{\mathrm{x}}(+)$ corresponds to the sum of the factors at their highest level $(+1)$ and $\Sigma_{\mathrm{x}}(-)$ to the sum of the factors at their lowest level and $n / 2$ for the half of the number of measurements. In addition, interaction between factors was also elucidated by calculating the effect of the first factor at the lowest level of the second factor and subtracting it from the effect of the first factor at the highest level of the second factor.

Morphology studies. MEM-NP were observed by transmission electron microscopy (TEM) on a Jeol 1010. To visualize the NP, copper grids were activated with UV light and samples were placed on the grid surface. Negative staining was performed with uranyl acetate $(2 \% \mathrm{w} / \mathrm{v}){ }^{[28]}$ 


\section{WILEY-VCH}

AFM studies. AFM analysis was performed in a multimode 8 microscopy with Nanoscope V electronics (Bruker, Germany). The microscope mode used was the peak Force tapping mode.with an SNL tip (Bruker). The samples were previously diluted (1:10) and about 5 $\mu \mathrm{l}$ of the solution were dropped to freshly cleaved mica surface and incubated for $5 \mathrm{~min}$. Afterwards, the sample was blown off with air.

DSC studies. DSC was performed in an aluminum pan on a DSC-821 (Mettler Toledo) under nitrogen atmosphere.

${ }^{1}$ H NMR studies. ${ }^{1} \mathrm{H}-\mathrm{NMR}$ was used to confirm both PLGA-PEG structure on the NP and drug incorporation. MEM-NP were centrifuged and dissolved in $\mathrm{D}_{2} \mathrm{O}$. The spectrum was recorded at $298 \mathrm{~K}$ on a Varian Inova $500 \mathrm{MHz}$ spectrometer (Agilent Technologies, Santa Clara, CA, USA). ${ }^{[19]}$

Stability studies. MEM-NP stability was assessed by light backscattering by means of a Turbiscan ${ }^{\circledR}$ Lab. For this purpose, a glass measurement cell was filled with $20 \mathrm{ml}$ of MEM-NP. The light source, pulsed near infrared light-emitting diode LED $(\lambda=880 \mathrm{~nm})$, was received by a backscattering detector at an angle of $45^{\circ}$ from the incident beam. Readings were carried out every hour for $24 \mathrm{~h}^{[31]}$

In vitro drug release. In vitro release of memantine from MEM-NPs was evaluated using the dialysis bag technique under sink conditions and results compared to free memantine. ${ }^{[63,64]}$ The release medium was composed of a PBS buffer solution (PBS 0.1 $\mathrm{M}, \mathrm{pH}$ 7.4) and temperature maintained at $32^{\circ} \mathrm{C}$ (ocular surface temperature) with stirring. At predetermined time intervals, $1 \mathrm{ml}$ samples were withdrawn from the reaction mixture 


\section{WILEY-VCH}

and replaced with $1 \mathrm{~mL}$ of fresh buffer. The memantine content of each aliquot was evaluated using Graphpad Prism v5.0.

Corneal and scleral permeation. Ex vivo corneal and scleral permeation experiments were carried out using New Zealand rabbits (male, weighting 2.5-3.0 kg), under veterinary supervision. Rabbits were anesthetized with intramuscular administration of ketamine $\mathrm{HCl}(35 \mathrm{mg} / \mathrm{kg})$ and xylazine $(5 \mathrm{mg} / \mathrm{kg})$ and euthanized by an overdose of sodium pentobarbital $(100 \mathrm{mg} / \mathrm{kg})$. The cornea and sclera of the animals were excised and fixed between the donor and receptor compartments of Franz diffusion cells (available permeation area of $0.64 \mathrm{~cm}^{2}$ ). The receptor compartment was filled with Bicarbonate Ringer's (BR) solution and kept at 32 and $37 \pm 0.5^{\circ} \mathrm{C}$ for corneal and scleral permeation respectively. $1 \mathrm{ml}$ of the formulation was placed in the donor compartment and $300 \mu \mathrm{l}$ were withdrawn from the receptor chamber at fixed time points and immediately replaced by BR. The cumulative drug amount permeated was calculated at each time point from the drug in the receiving medium and plotted as function time. ${ }^{[26,66]}$ All experiments using rabbits were performed according to the Ethics Committee of Animal Experimentation at the University of Barcelona. The amount of memantine retained in the tissues was also determined by extracting the drug from the tissue with methanol: water $(75: 25, \mathrm{v} / \mathrm{v})$ under sonication for 30 minutes. ${ }^{[30]}$

Cytotoxicity assay. Human retinoblastoma cells (Y-79) and adherent human keratinocyte cells (HaCaT ${ }^{[73]}$ ) were purchased from Cell Lines Services (CLS, Eppelheim, Germany) and were maintained in RPMI-1640 and DMEM media respectively. Cell viability was assayed with Alamar Blue (Alfagene, Invitrogene, Portugal) at 24 and $48 \mathrm{~h}$ as was 


\section{WILEY-VCH}

previously described. ${ }^{[27,68]}$ Data was analyzed by calculating cell viability through the percentage of Alamar blue reduction compared to the control (untreated cells). ${ }^{[75,76]}$

Ocular tolerance test: HET-CAM and Draize irritation test. In order to evaluate the risk of ocular irritation caused by free memantine and MEM-NP administered as eye drops, ocular tolerance tests in vivo and in vitro were conducted. Ocular tolerance was assessed in vitro using the HETCAM ${ }^{\circledR}$ test (Figure 4 of supplementary material). ${ }^{[31]}$ Scores of irritation potential were grouped into four categories. ${ }^{[31]}$ Subsequent in vivo ocular tolerance assays were performed using primary eye irritation test of Draize et. al (1994) with New Zealand rabbits (male, $2.5 \mathrm{~kg}$ ) (n=3/group). ${ }^{[33]}$ The formulation was instilled in the conjunctival sac of the right eye and a gentle massage was applied. The appearance of irritation was observed at the time of administration and after 1 hour, using the left eye as a negative control. The OII was calculated by direct observation of the anterior segment of the eye, noting the possible injury of the conjunctiva, iris and cornea. ${ }^{[33]}$

In vivo studies: therapeutic efficacy. Induced glaucoma experimental models such as Morrison model of ocular hypertension were previously validated by our group. ${ }^{[48]}$ Adult male DA rats weighing 150 to $200 \mathrm{~g}$ were treated with procedures approved by the U.K. Home Office and in compliance with the ARVO Statement for the Use of Animals in Ophthalmic and Vision Research. For the present study 10 rats were used as control without glaucoma induction, and 20 rats underwent surgery to elevate intraocular pressure (IOP) by injection of hypertonic saline solution $(1.80 \mathrm{M})$ into two episcleral veins. The rats undergoing chronic ocular hypertension were divided in two groups (10 rats/group): control group (treated with saline serum) and MEM-NPs group (treated with two drops of MEM-NPs/day). Contralateral unoperated eyes were also used as a control. The IOP 


\section{WILEY-VCH}

of both eyes was measured weekly using a Tonopen XL (Medtronic Solan, Jacksonville, FL).

Histology and RGC quantification. Animals were sacrificed three weeks after OHT induction. Eyes were enucleated and fixed in $4 \%$ fresh paraformaldehyde overnight. Whole-mount retinas were stained for the RGC specific nuclear-localized transcription factor Brn3a using a MAB1585 antibody (1:350; Merck Millipore). Immunoreactivity was detected with AlexaFluor ${ }^{\circledR} 555$ donkey anti-mouse (1:200; Merck Millipore, Darmstadt, Germany). Retinas were mounted and examined under confocal microscopy (LSM 710; Carl Zeiss Micro Imaging GmbH, Jena, Germany) as a tiled z-stack at 10x magnification generating a single plane maximum projection of the RGC layers for subsequent analysis. Image acquisition settings were kept constant for all retinas imaged, allowing comparison of Brn3a expression in each experimental group. ${ }^{[34]}$ Automatic quantification of Brn3a-labelled RGC was achieved using an algorithm previously validated. ${ }^{[34,77]}$ Naïve and OHT only Brn-3a whole retinal counts from DA rats was obtained from our previous work ${ }^{[34]}$.

Statistical analysis. Statistical evaluation of data was performed using one-way analysis of variance (ANOVA) with Tukey multiple comparison post-hoc test to assess differences between groups and $p<0.05$ was considered significant.

\section{Acknowledgements}




\section{WILEY-VCH}

This work was supported by the Spanish Ministry of Science and Innovation (MAT 201459134-R and SAF-2016-33307). MLG, ACC, ME, MAE and ESL belong to 2014SGR1023. The first author, ESL, acknowledges the support of the Spanish Ministry for the PhD scholarship FPI-MICINN (BES-2012-056083). The authors want to acknowledge the Portuguese Science and Technology Foundation (FCT/MCT) and European Funds (PRODER/COMPETE) under the projects UID/AGR/04033/2013, M-ERA-NET0004/2015-PAIRED and UID/QUI/50006/2013, co-financed by FEDER, under the partnership Agreement PT2020.

Received: ((will be filled in by the editorial staff)) Revised: ((will be filled in by the editorial staff)) Published online: ((will be filled in by the editorial staff)) 
References

[1] H. Celiker, N. Yuksel, S. Solakoglu, L. Karabas, F. Aktar, Y. Caglar, J. Ophthalmic Vis. Res. 2016, 11, 174.

[2] B. M. Davis, L. Crawley, M. Pahlitzsch, F. Javaid, M. F. Cordeiro, Acta Neuropathol. 2016, 132, 807.

[3] M. Almasieh, A. M. Wilson, B. Morquette, J. L. Cueva Vargas, A. Di Polo, Prog. Retin. Eye Res. 2012, 31, 152.

[4] D. R. Anderson, Curr. Opin. Ophthalmol. 2003, 14, 86.

[5] T. Salt, M. Cordeiro, Eye 2006, 20, 730.

[6] T. Krupin, J. M. Liebmann, D. S. Greenfield, R. Ritch, S. Gardiner, Am. J. Ophthalmol. 2011, 151, 671 .

[7] K. Tian, S. Shibata-, M. Pahlitzsch, M. F. Cordeiro, S. Shibata-Germanos, M. Pahlitzsch, M. F. Cordeiro, Clin. Ophthalmol. 2015, 9, 2109.

[8] J. Folch, D. Petrov, M. Ettcheto, S. Abad, E. Sánchez-López, M. L. García, J. Olloquequi, C. Beas-zarate, C. Auladell, A. Camins, Neural Plast. 2016, $2016,1$.

[9] G. Chidlow, J. P. M. Wood, R. J. Casson, Drugs 2007, 67, 725.

[10] D. F. Sena, K. Lindsley, Cochrane database Syst. Rev. 2013, 1.

[11] N. N. Osborne, Acta Ophthalmol. 2009, 87, 450.

[12] S. Mcnally, C. J. O. Brien, Drug Discov. Today Dis. Model. 2013, 10, e207.

[13] E. Prieto, B. Puente, A. Uixera, J. A. Garcia de Jalon, S. Perez, L. Pablo, J. M. Irache, M. A. Garcia, M. A. Bregante, Ophthalmic Res. 2012, 48, 109.

[14] D. Manickavasagam, M. O. Oyewumi, J. Drug Deliv. 2013, 2013, 1.

[15] U. B. Kompella, A. C. Amrite, R. Pacha Ravi, S. A. Durazo, Prog. Retin. Eye Res. 2013, 36, 172.

[16] B. Davis, E. Normando, L. Guo, P. O’Shea, S. Moss, S. Somavarapu, M. Cordeiro, Small 2014, 10, 1575.

[17] H. Yang, P. Tyagi, R. S. Kadam, C. A. Holden, U. B. Kompella, ACS Nano 2012 , 6, 7595 . 
[18] G. Singh, T. Kaur, R. Kaur, A. Kaur, Int. J. Pharmacol. Pharm. Sci. 2014, 1, 30.

[19] A. Vasconcelos, E. Vega, Y. Pérez, M. J. Gómara, M. L. García, I. Haro, Int. J. Nanomedicine 2015, 10, 609.

[20] E. Prieto, B. Puente, A. Uixera, S. Perez, L. Pablo, J. M. Irache, M. a Garcia, M. a Bregante, V. Faculty, V. Faculty, Opthalmic Res. 2012, 48, 109.

[21] E. Cohen-Sela, M. Chorny, N. Koroukhov, H. D. Danenberg, G. Golomb, J. Control. release 2009, 133, 90.

[22] H. Puthusserickal, R. Suman, V. Gunjan, Langmuir 2015, 31, 3.

[23] H. E. Gottlieb, V. Kotlyar, A. Nudelman, J. Org. Chem. 1997, 62, 7512.

[24] F. J. Mcinnes, N. G. Anthony, R. Kennedy, N. J. Wheate, Org. Biomol. Chem. 2010, 8,765 .

[25] D. H. Kim, M. Kim, C. Choi, C. Chung, S. H. Ha, C. H. Kim, Nanoscale Res. Lett. 2012, 7, 1 .

[26] Y. Li, Y. Pei, X. Zhang, Z. Gu, H. Zhou, W. Yuan, J. Zhou, J. Zhu, X. Gao, J. Control. Release 2001, 71, 203.

[27] J. J. Pillai, A. K. T. Thulasidasan, R. J. Anto, N. C. Devika, N. Ashwanikumar, G. S. V. Kumar, RSC Adv. 2015, 5, 25518.

[28] A. Parra, M. Mallandrich, B. Clares, M. A. Egea, M. Espina, M. L. García, A. C. Calpena, Colloids Surf. B. Biointerfaces 2015, 136, 935.

[29] M. L. Viger, W. Sheng, C. L. McFearin, M. Y. Berezin, A. Almutair, J. Control. release 2013, 171, 308 .

[30] G. Abrego, H. Alvarado, E. B. Souto, B. Guevara, L. Halbaut, A. Parra, A. C. Calpena, M. L. García, Eur. J. Pharm. Biopharm. 2015, $231,1$.

[31] E. Sánchez-López, M. A. Egea, A. Cano, M. Espina, A. C. Calpena, M. Ettcheto, A. Camins, E. B. Souto, A. M. Silva, M. L. García, Colloids Surfaces B Biointerfaces 2016, 145, 241.

[32] B. McKenzie, G. Kay, K. H. Matthews, R. M. Knott, D. Cairns, Int. J. Pharm. 2015, 490, 1 .

[33] A. M. D. Nóbrega, E. N. Alves, R. D. F. Presgrave, R. N. Costa, I. F. Delgado, 
Brazilian Arch. Biol. Technol. 2012, 55, 381.

[34] B. Davis, L. Guo, J. Brenton, L. Langley, E. Normando, M. Cordeiro, Cell Death Discov. 2016, 2, 1.

[35] H. Scientific, Horiba Instruments, Inc 2016, 1.

[36] J. Jiang, G. Oberdörster, P. Biswas, J. Nanoparticle Res. 2009, 11, 77.

[37] G. R. Ramos Yacasi, A. C. Calpena Campmany, M. A. Egea Gras, M. Espina García, M. L. García López, Drug Dev. Ind. Pharm. 2017, 43, 637.

[38] E. Vega, M. A. Egea, A. C. Calpena, M. Espina, M. L. García, Int. J. Nanomedicine 2012, 7, 1357.

[39] G. Abrego, H. L. Alvarado, M. A. Egea, E. Gonzalez-Mira, A. C. Calpena, M. L. Garcia, J. Pharm. Sci. 2014, 103, 3153.

[40] J. Araújo, E. Vega, C. Lopes, M. A. Egea, M. L. Garcia, E. B. Souto, Colloids Surf. B. Biointerfaces 2009, 72, 48.

[41] M. Vidal-Sanz, M. Salinas-Navarro, F. M. Nadal-Nicolás, L. Alarcón-Martínez, F. J. Valiente-Soriano, J. Miralles de Imperial, M. Avilés-Trigueros, M. AgudoBarriuso, M. P. Villegas-Pérez, Prog. Retin. Eye Res. 2012, 31, 1.

[42] C. Galindo-Romero, M. Harun-Or-Rashid, M. Jiménez-López, M. Vidal-Sanz, M. Agudo-Barriuso, F. Hallböök, PLoS One 2016, 11, 1.

[43] M. J. Pérez de Lara, C. Santano, A. Guzmán-Aránguez, F. J. Valiente-Soriano, M. Avilés-Trigueros, M. Vidal-Sanz, P. de la Villa, J. Pintor, Exp. Eye Res. 2014, 122, 40.

[44] M. Ishikawa, T. Yoshitomi, C. F. Zorumski, Y. Izumi, Biomed Res. Int. 2015, 2015, 1.

[45] P. Boya, L. Esteban-martínez, A. Serrano-puebla, R. Gómez-Sintes, B. Villarejozori, Prog. Retin. Eye Res. 2016, 55, 206.

[46] L. Guo, S. E. Moss, R. A. Alexander, R. R. Ali, F. W. Fitzke, M. F. Cordeiro, Invest. Ophthalmol. Vis. Sci. 2005, 46, 175.

[47] H.-Y. Li, Y.-W. Ruan, C.-R. Ren, Q. Cui, K.-F. So, Neural Regen Res 2014, 9, 565. 
[48] L. Guo, T. E. Salt, A. Maass, V. Luong, S. E. Moss, F. W. Fitzke, M. F. Cordeiro, Invest. Ophthalmol. Vis. Sci. 2006, 47, 626.

[49] J. W. Johnson, S. E. Kotermanski, Curr. Opin. Pharmacol. 2006, 6, 61.

[50] G. M. Alley, J. a Bailey, D. Chen, B. Ray, L. K. Puli, H. Tanila, P. K. Banerjee, D. K. Lahiri, J. Neurosci. Res. 2010, 88, 143.

[51] B. Ray, P. K. Banerjee, N. H. Greig, D. K. Lahiri, Neurosci. Lett. 2010, 470, 1.

[52] K. Ito, T. Tatebe, K. Suzuki, T. Hirayama, M. Hayakawa, H. Kubo, T. Tomita, M. Makino, Eur. J. Pharmacol. 2017, 798, 16.

[53] L. Guo, T. E. Salt, V. Luong, N. Wood, W. Cheung, A. Maass, G. Ferrari, A. M. Sillito, M. E. Cheetham, S. E. Moss, F. W. Fitzke, M. F. Cordeiro, F. Russo-Marie, Proc. Natl. Acad. Sci. U. S. A. 2007, 104, 13444.

[54] Y. Ito, M. Shimazawa, K. Tsuruma, C. Mayama, K. Ishii, H. Onoe, M. Aihara, M. Araie, H. Hara, Mol. Vis. 2012, 18, 2647.

[55] S. Nizari, L. Guo, B. M. Davis, E. M. Normando, J. Galvao, L. A. Turner, M. Bizrah, M. Dehabadi, K. Tian, M. Francesca Cordeiro, Cell Death Dis. 2016, 7, e2514.

[56] V. Gupta, V. B. Gupta, N. Chitranshi, S. Gangoda, R. Vander Wall, M. Abbasi, M. Golzan, Y. Dheer, T. Shah, A. Avolio, R. Chung, R. Martins, S. Graham, Cell. Mol. Life Sci. 2016, 73, 4279.

[57] J. M. Sivak, Wei EQ, Zhang WP, K. SS., T. BS., S. RH., Investig. Opthalmology Vis. Sci. 2013, 54, 871.

[58] J. A. Ratnayaka, L. C. Serpell, A. J. Lotery, Eye (Lond). 2015, 29, 1013.

[59] G. Beidoe, S. A. Mousa, Clin. Ophthalmol. 2012, 6, 1699.

[60] J. Won-Kyu, K. Keun-Young, M. Angert, K. Duong Polk, J. D. Lindsey, M. H. Ellisman, R. N. Weinreb, Invest Ophthalmol Vis. Sci. 2009, 50, 707.

[61] F. Schuettauf, K. Quinto, R. Naskar, D. Zurakowski, Vision Res. 2002, 42, 2333.

[62] W. Hare, E. WoldeMussie, R. Lai, H. Ton, G. Ruiz, B. Feldmann, M. Wijono, T. Chun, L. Wheeler, Surv. Ophthalmol. 2001, 45, S284.

[63] N. N. Osborne, Vis. Neurosci. 1999, 16, 45. 
[64] B. T. Gabelt, C. A. Rasmussen, O. Y. Tektas, C. B. Y. Kim, J. C. Peterson, T. Michael Nork, J. N. ver Hoeve, E. Lütjen-Drecoll, P. L. Kaufman, Investig. Ophthalmol. Vis. Sci. 2012, 53, 2368.

[65] U. Puangthong, G.-Y. R. Hsiung, Neuropsychiatr. Dis. Treat. 2009, 5, 553.

[66] P. V Turner, T. Brabb, C. Pekow, M. a Vasbinder, J Am Assoc Lab Anim Sci 2011, 50,600 .

[67] S. Laserra, A. Basit, P. Sozio, L. Marinelli, E. Fornasari, I. Cacciatore, M. Ciulla, H. Türkez, F. Geyikoglu, A. Di, Int. J. Pharm. 2015, 485, 183.

[68] N. Mittapelly, R. Rachumallu, G. Pandey, S. Sharma, A. Arya, R. S. Bhatta, P. R. Mishra, Eur. J. Pharm. Biopharm. 2016, 101, 62.

[69] H. Ali, B. Weigmann, E. M. Collnot, S. A. Khan, M. Windbergs, C. M. Lehr, Pharm. Res. 2015, 1.

[70] A. A. Almeida, D. R. Campos, G. Bernasconi, S. Calafatti, F. A. P. Barros, M. N. Eberlin, E. C. Meurer, E. G. Paris, J. Pedrazzoli, J. Chromatogr. B. Analyt. Technol. Biomed. Life Sci. 2007, 848, 311.

[71] K. Hu, S. Cao, F. Hu, J. Feng, Int. J. Nanomedicine 2012, 7, 3537.

[72] M. Teixeira, M. J. Alonso, M. M. M. Pinto, C. M. Barbosa, Eur. J. Pharm. Biopharm. 2005, 59, 491.

[73] P. Boukamp, P. Rule T, D. Breitkreutz, J. Hornung, A. Markham, N. E. Fusenig, J. Cell Biol. 1988, 106, 761.

[74] S. Doktorovová, D. L. Santos, I. Costa, T. Andreani, E. B. Souto, A. M. Silva, Int. J. Pharm. 2014, 471, 18.

[75] C. M. Emnett, L. N. Eisenman, J. Mohan, A. a. Taylor, J. J. Doherty, S. M. Paul, C. F. Zorumski, S. Mennerick, Br. J. Pharmacol. 2015, 172, 1333.

[76] W. Liu, Z. Xu, T. Yang, B. Xu, Y. Deng, S. Feng, Mol. Neurobiol. 2016, 2, DOI 10.1007/s12035-016-0020-2.

[77] L. Guo, B. Davis, S. Nizari, E. M. Normando, H. Shi, J. Galvao, L. Turner, J. Shi, M. Clements, S. Parrinello, M. F. Cordeiro, Cell Death Dis. 2014, 5, e1460. 
WILEY-VCH 
Table 1. Characteristics of memantine loaded nanoparticles. Design of experiments matrix and results according to central factorial design to study $\mathrm{pH}$ influence of the inner and external water phases (MEM-NP prepared with 20mg/mL PLGA-PEG and 5mg/mL of MEM)

\begin{tabular}{|c|c|c|c|c|c|c|c|c|c|}
\hline & $\mathrm{pH} \mathrm{w}_{1}$ & $\mathrm{pH} \mathrm{w}_{2}$ & $\mathrm{Z}_{\mathrm{av}}(\mathrm{nm})$ & $\mathrm{PI}$ & $\mathrm{ZP}(\mathrm{mV})$ & $\mathrm{EE}(\%)$ \\
\hline \multicolumn{7}{|c|}{ Factorial points } \\
\hline F1 & 12.0 & +1 & 3.5 & -1 & $234.0 \pm 0.6$ & $0.09 \pm 0.02$ & $-5.67 \pm 0.28$ & 78.45 \\
\hline F2 & 12.0 & +1 & 6.5 & +1 & $225.4 \pm 1.2$ & $0.04 \pm 0.02$ & $-5.65 \pm 0.12$ & 79.60 \\
\hline F3 & 12.0 & +1 & 5.0 & 0 & $197.9 \pm 3.64$ & $0.03 \pm 0.02$ & $-5.17 \pm 0.06$ & 79.43 \\
\hline F4 & 10.0 & -1 & 6.5 & +1 & $221.3 \pm 4.01$ & $0.18 \pm 0.02$ & $-5.19 \pm 0.16$ & 80.81 \\
\hline F5 & 10.0 & -1 & 3.5 & -1 & $268.3 \pm 4.83$ & $0.21 \pm 0.02$ & $-5.87 \pm 0.19$ & 79.03 \\
\hline F6 & $\mathbf{1 1 . 0}$ & $\mathbf{0}$ & $\mathbf{6 . 5}$ & $\mathbf{+ 1}$ & $\mathbf{1 9 3 . 1} \pm \mathbf{0 . 4 2}$ & $\mathbf{0 . 0 5} \pm \mathbf{0 . 0 1}$ & $-\mathbf{4 . 4 1} \pm \mathbf{0 . 1 5}$ & $\mathbf{8 0 . 6 4}$ \\
\hline F7 & 11.0 & 0 & 3.5 & -1 & $196.1 \pm 3.33$ & $0.04 \pm 0.01$ & $-4.39 \pm 0.26$ & 78.40 \\
\hline F8 & 10.0 & -1 & 5.0 & 0 & $198.7 \pm 3.03$ & $0.12 \pm 0.01$ & $-4.82 \pm 0.61$ & 77.86 \\
\hline Center points & & & & & \\
\hline F9 & 11.0 & 0 & 5.0 & 0 & $217.9 \pm 1.5$ & $0.11 \pm 0.02$ & $-5.03 \pm 0.33$ & 80.34 \\
\hline F10 & 11.0 & 0 & 5.0 & 0 & $219.5 \pm 2.4$ & $0.14 \pm 0.01$ & $-5.08 \pm 0.24$ & 79.99 \\
\hline
\end{tabular}



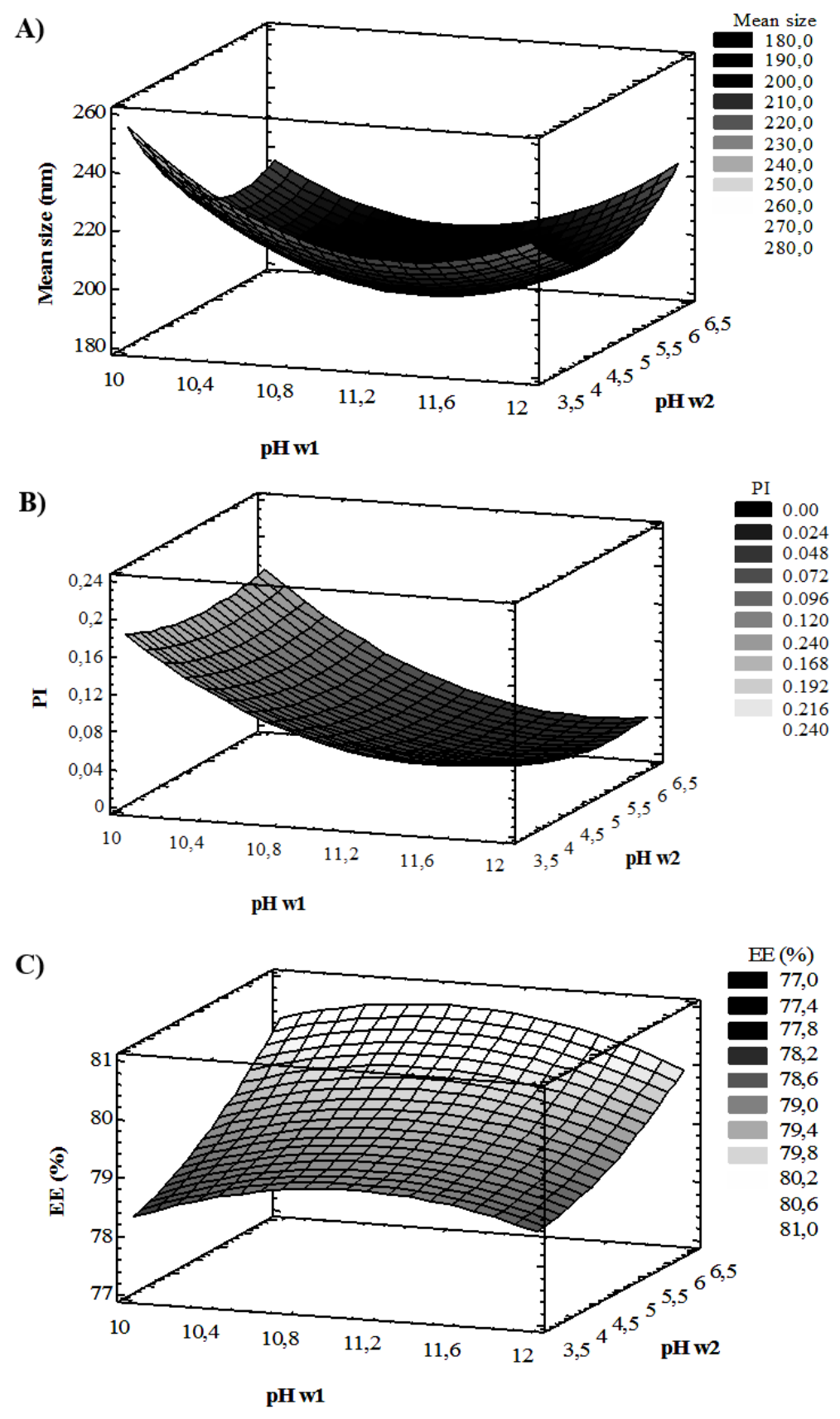

Figure 1. Characteristics of memantine loaded nanoparticles in response to changes in pH of w1 and w2 phases. Results from DoE experiments regarding the influence of $\mathrm{pH}$ on double emulsion solvent evaporation method. The effect of $\mathrm{pH}$ on mean MEM-NP [A] diameter, [B] polydispersity (PI) and [C] Encapsulation Efficiency (EE) was investigated. 


\section{WILEY-VCH}

[A]

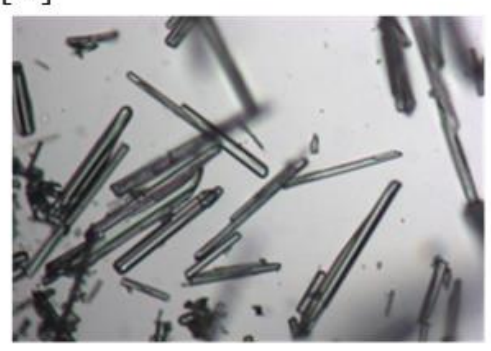

$[\mathrm{C}]$

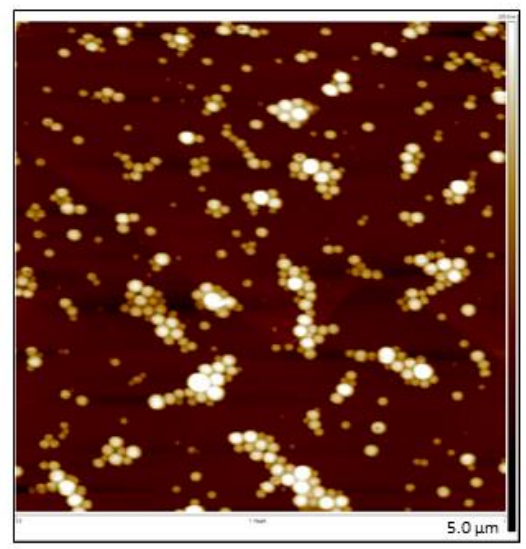

[B]

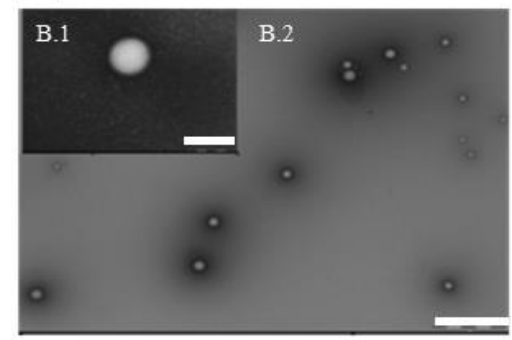

[D]

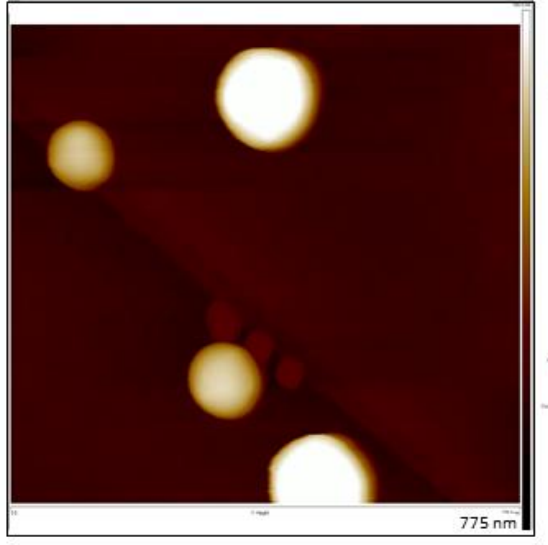

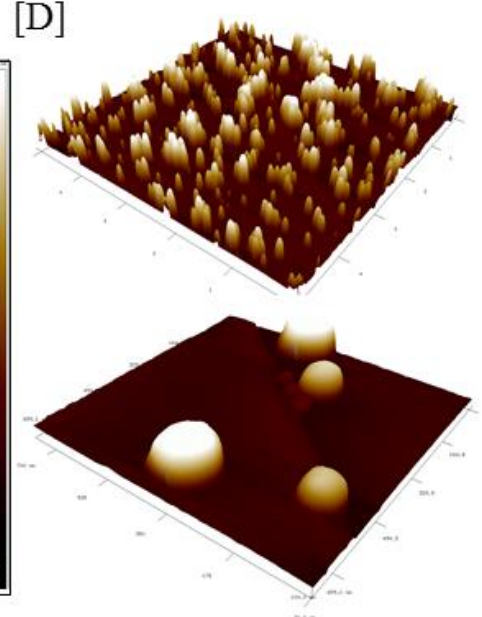

Figure 2. Transmission electron microscopy and Atomic force microscopy of MEM NP.

[A] Micrograph confirming the crystalline structure of free memantine, [B] TEM micrograph illustrating the spherical structure of memantine loaded nanoparticles (MEM-NP), scale bar of B.1) corresponding to $500 \mathrm{~nm}$ and B.2) $1 \mu \mathrm{m}$. [C] 2D AFM microsgraph MEM NP, [D] 3D analysis corresponding to the $2 \mathrm{D}$ micrographs. 
WILEY-VCH

$[\mathrm{A}]$

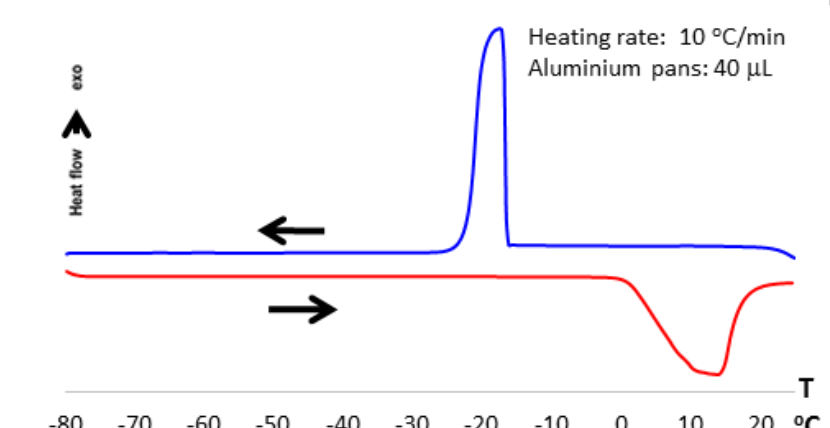

$\begin{array}{llllllllllll}-80 & -70 & -60 & -50 & -40 & -30 & -20 & -10 & 0 & 10 & 20 & { }^{\circ} \mathrm{C}\end{array}$

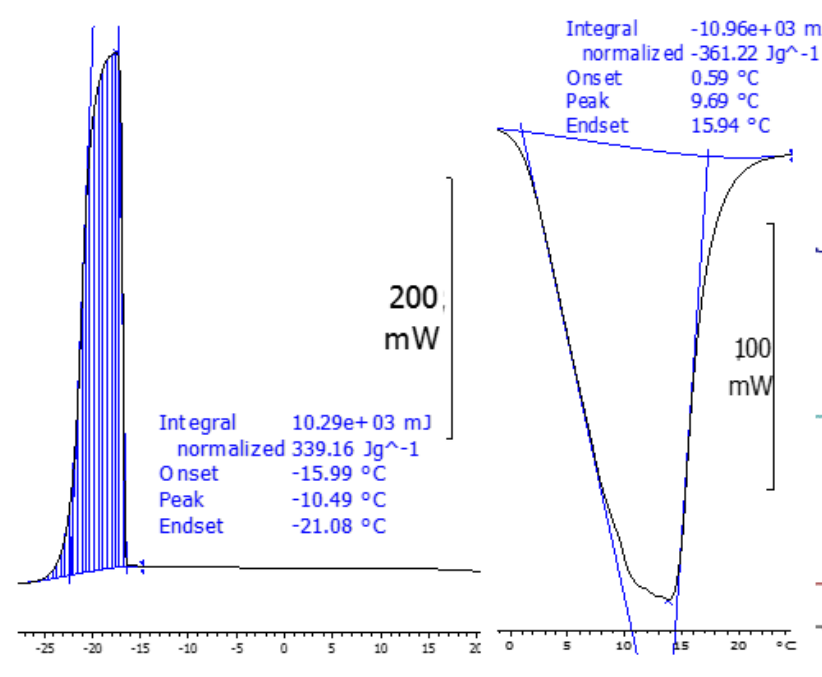

[B]

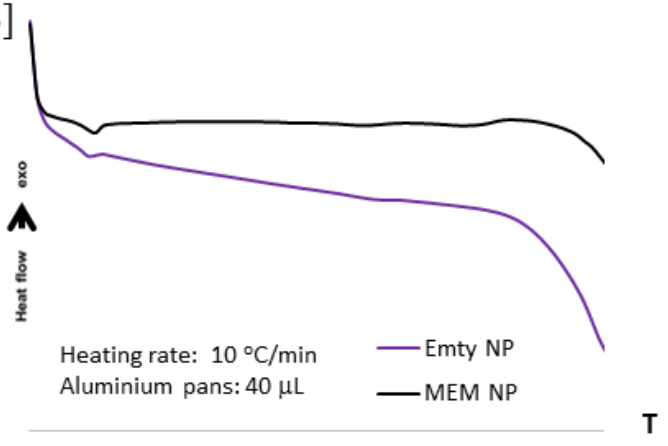

$\mathrm{T}$ $\begin{array}{lllllllllll}50 & 75 & 100 & 125 & 150 & 175 & 200 & 225 & 250 & 275 & 300\end{array}{ }^{\circ} \mathrm{C}$ $[\mathrm{C}]$

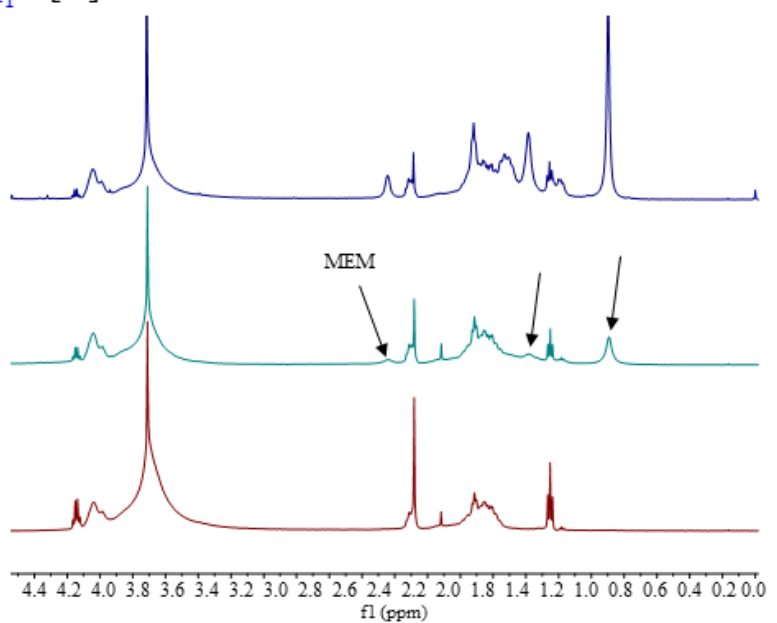

Figure 3. [A] DSC curves starting at $25{ }^{\circ} \mathrm{C}$ (freezing until $-80{ }^{\circ} \mathrm{C}$ and heating until $25{ }^{\circ} \mathrm{C}$ at 10 ${ }^{\circ} \mathrm{C} / \mathrm{min}$ ) and [B] DSC curves of MEM NP and empty NP starting at $25{ }^{\circ} \mathrm{C}$ and heating until 300 ${ }^{\circ} \mathrm{C}$ (heating rate $10{ }^{\circ} \mathrm{C} / \mathrm{min}$ ) [C] ${ }^{1} \mathrm{H}-\mathrm{NMR}$ spectra of nanoparticles spiked with memantine, memantine loaded nanoparticles and empty nanoparticles. 


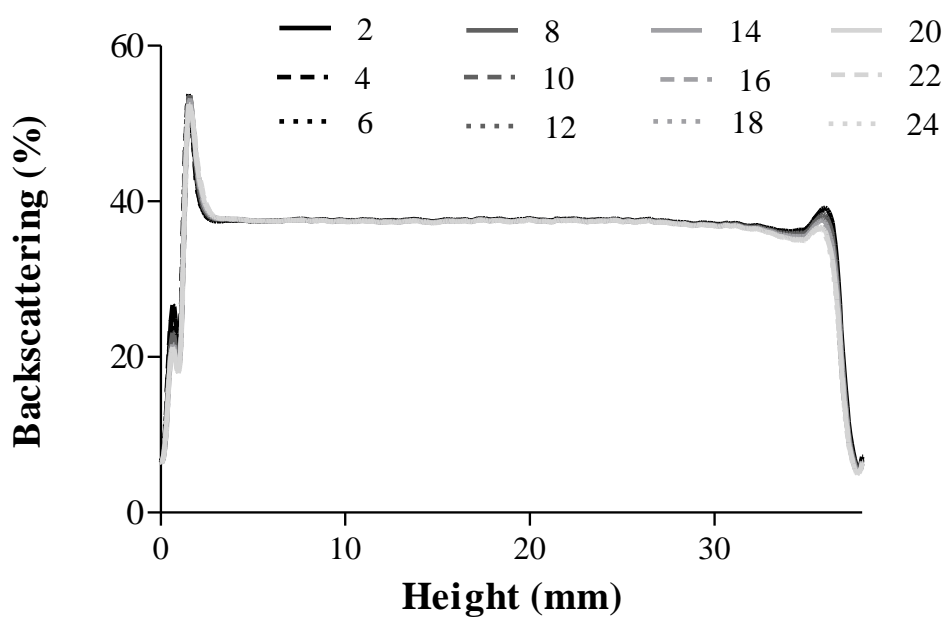

Figure 4. Backscattering profile of memantine loaded nanoparticles demonstrates the formulation remains stable when stored at room temperature for 24 hours. 
[A]

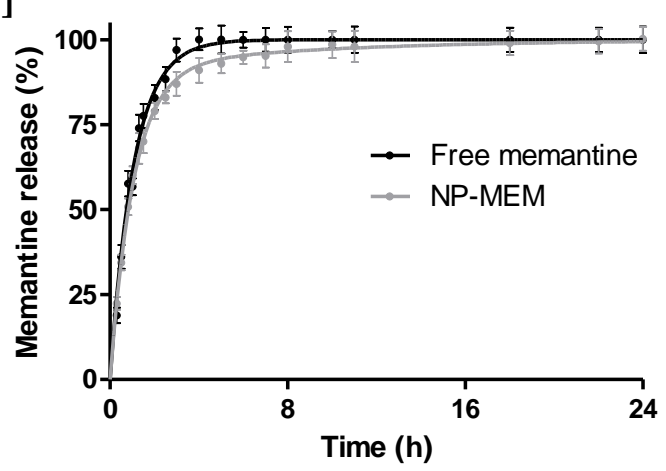

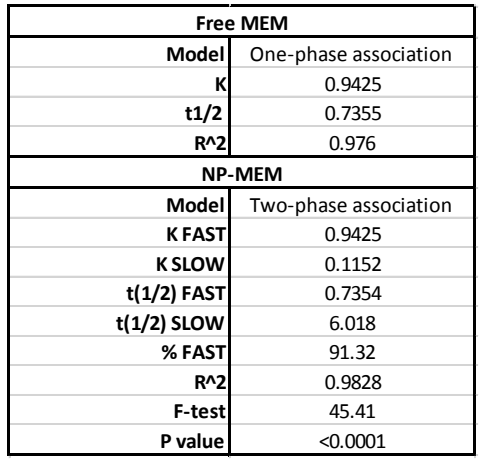

[C]

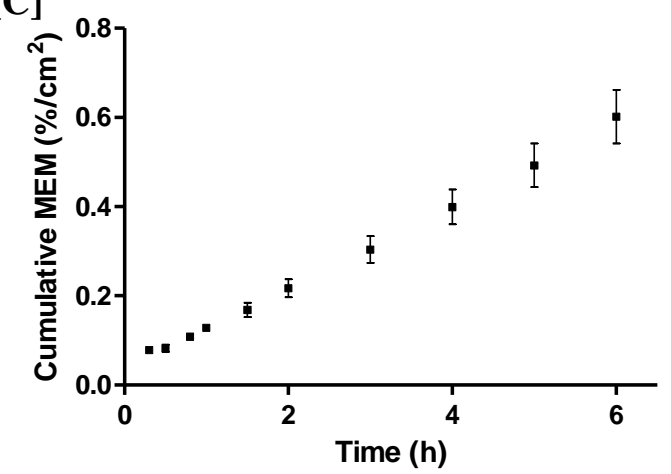

Figure 5. In vitro release of memantine and ex vivo permeation assays. [A] In vitro release of free memantine (MEM) versus memantine loaded nanoparticles (MEM-NP) adjusted to the best fit kinetic models (single-phase exponential association (eq.1) or two-phase exponential association (eq.2) respectively. Ex vivo assessment of the [B] corneal and [C] scleral permeation of MEM-NPs. 


\section{WILEY-VCH}

A)

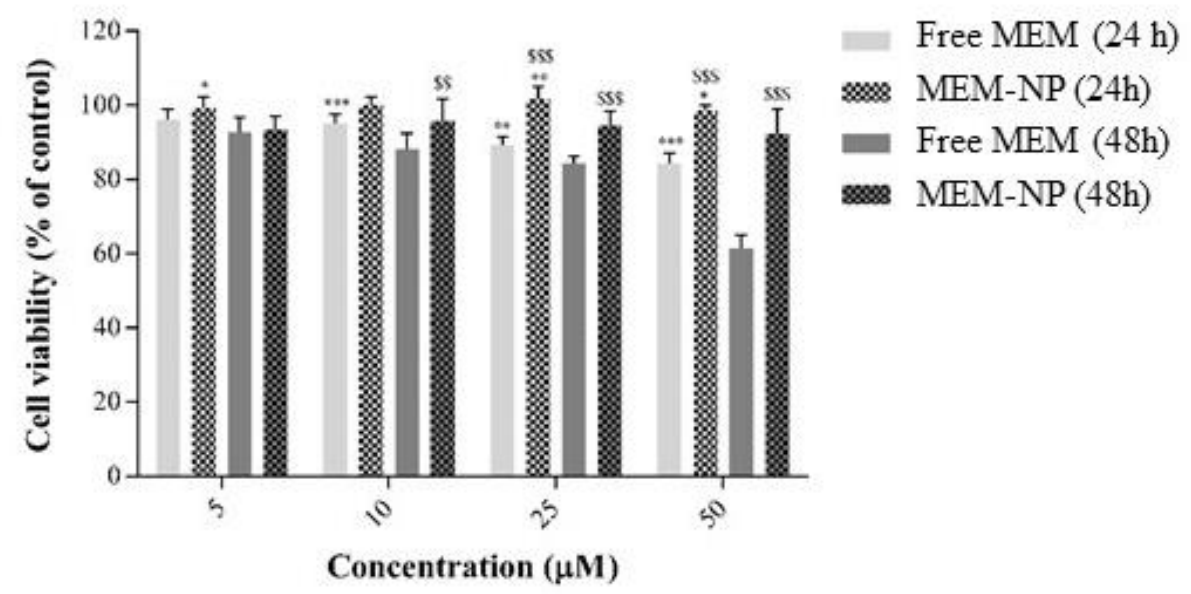

B)

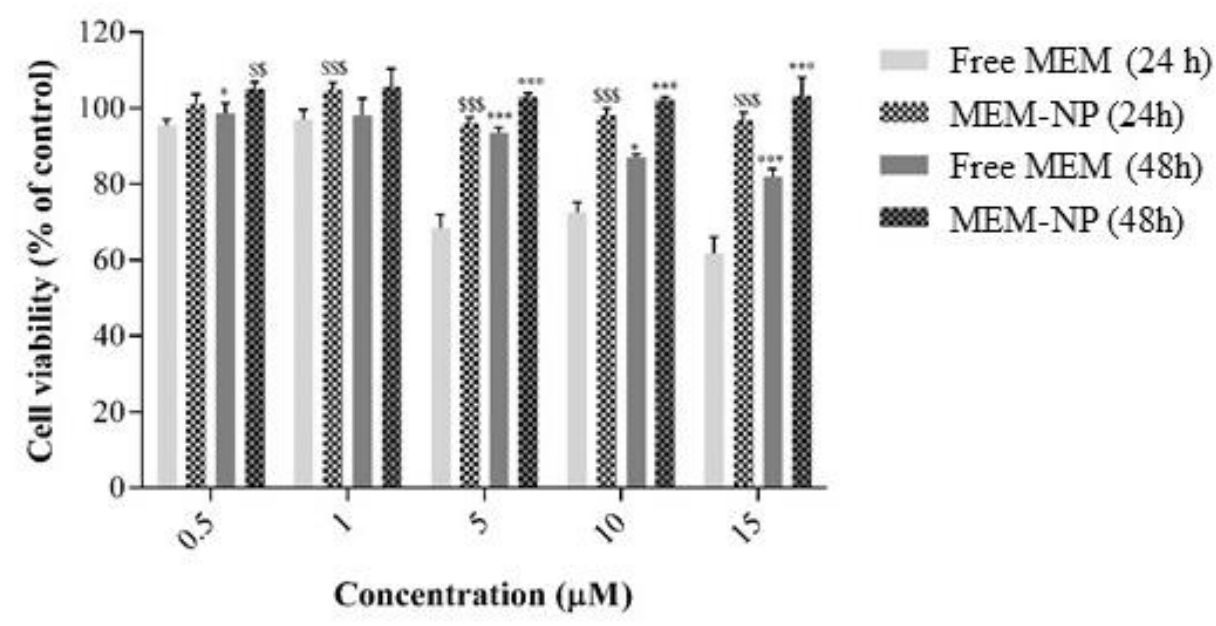

Figure 6. Memantine loaded nanoparticles are well tolerated by epithelial and neuronal cultures in vitro. Cell viability was assessed using the Alamar blue viability assay with the [A] keratinocyte cell line and [B] retinoblastoma cells. Values are expressed as mean \pm SD. Significant differences between free memantine (MEM) and MEM-NP at same exposure time and concentration are represented as ${ }^{\$} \mathrm{p}<0.05,{ }^{\$} \mathrm{p}<0.01$ and ${ }^{\$ \$} \mathrm{p}<0.001$ and ${ }^{\$ \$ \$} \mathrm{p}<0.0001$. Significant differences between the exposure time with same formulation and concentration are represented as $* \mathrm{p}<0.05, * * \mathrm{p}<0.01, * * * \mathrm{p}<0.001$ and $* * * * \mathrm{p}<0.0001$ 


\section{WILEY-VCH}

[A]

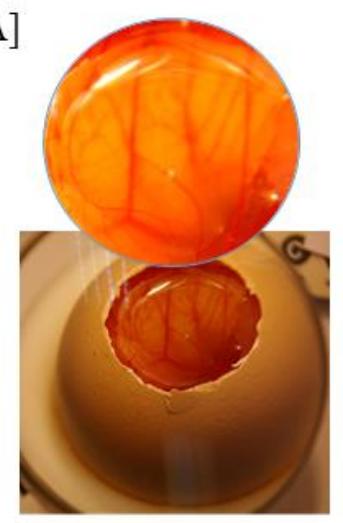

[B]

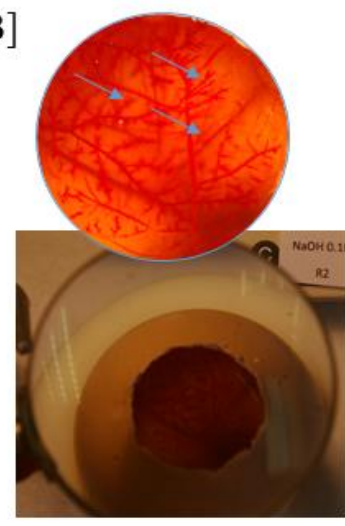

[C]

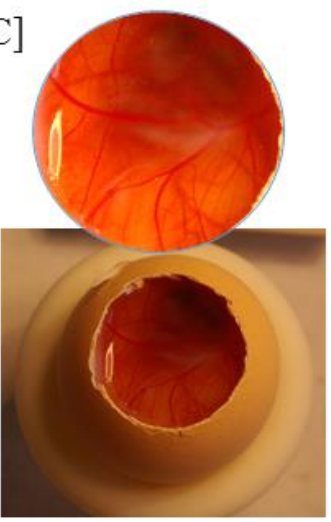

[D]

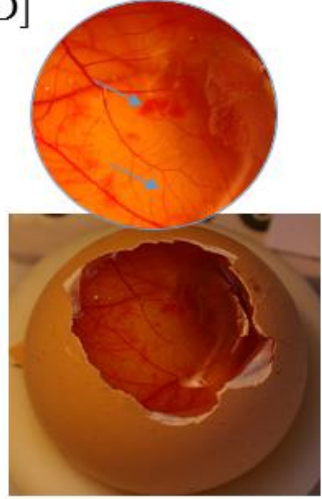

$[\mathrm{E}]$

\begin{tabular}{|c|c|c|c|}
\hline Formulation & Test & OII & Classification \\
\hline Free MEM & HET-CAM & $1.85 \pm 0.15$ & Slightly irritant \\
\cline { 2 - 4 } & Draize & $4.00 \pm 1.00$ & Slightly irritant \\
\hline \multirow{2}{*}{ MEM-NP } & HET-CAM & $0.13 \pm 0.01$ & Non-irritant \\
\hline & Draize & $0.00 \pm 0.00$ & Non-irritant \\
\hline
\end{tabular}

Figure 7. Ocular tolerance assessment of memantine and memantine loaded nanoparticles. HET-CAM test results 5 minutes after exposure of $0.3 \mathrm{~mL}$ of [A] $0.9 \%$ sodium cloride (negative control), [B] 1M sodium hydroxide (positive control), [C] memantine loaded nanoparticles (MEM-NP), [D] free memantine (MEM) memantine loaded nanoparticles (MEM-NP). [E] Classification of the ocular irritation potential in vitro and in vivo. 

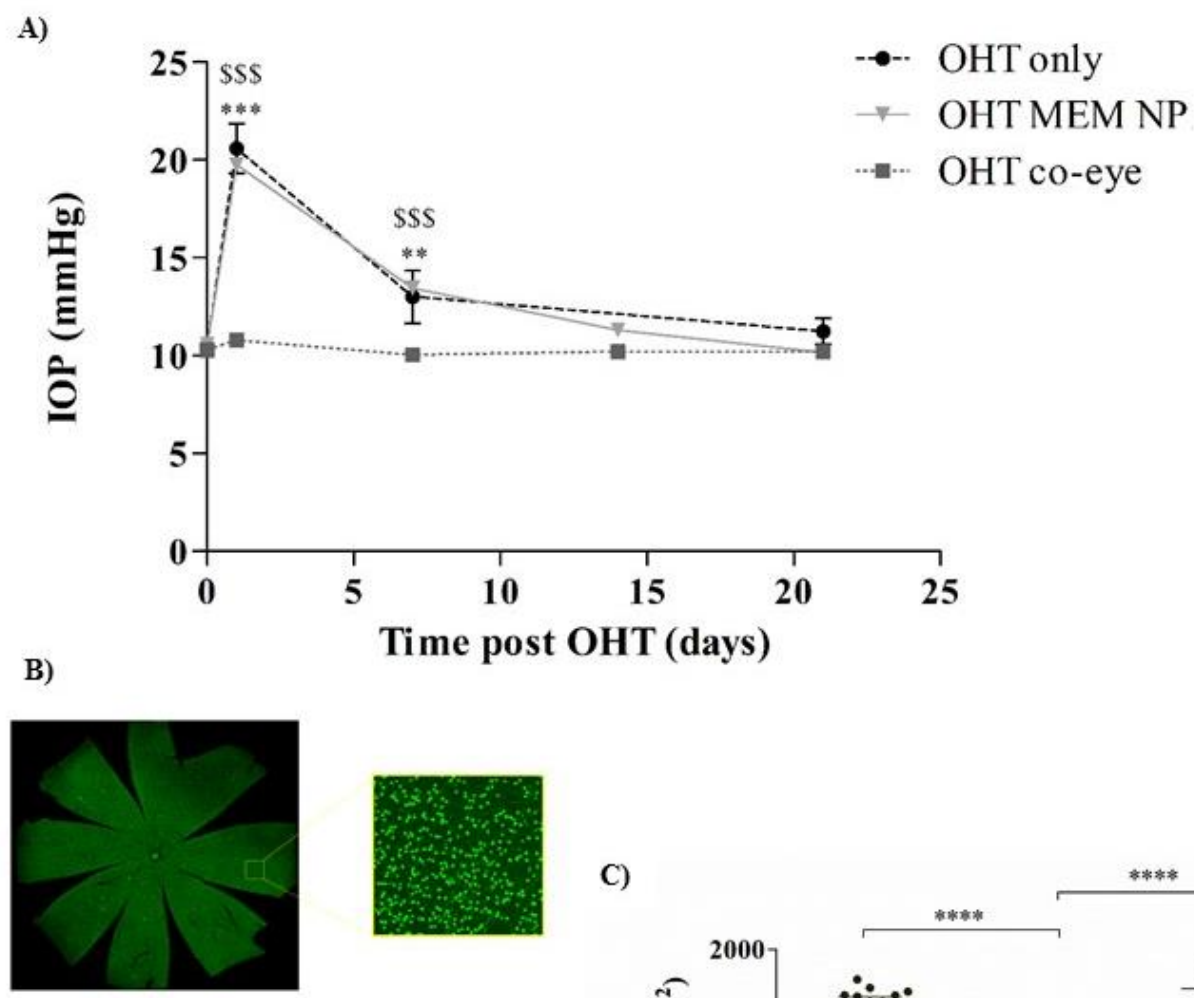

C)

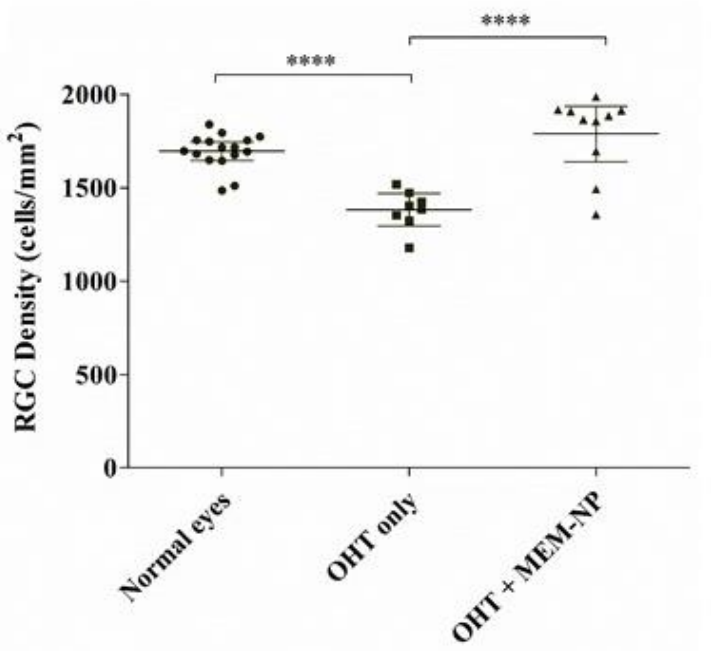

Figure 8. Topical administration of memantine loaded nanoparticles protects RGC soma against ocular hypertension induced cell loss. [A] IOP profiles of OHT only, OHT + MEM$\mathrm{NP}$ and OHT contralateral eyes. $* \mathrm{p}<0.05$, significant differences between OHT and the coeye; ${ }^{\$} \mathrm{p}<0.05$, significant differences between OHT and OHT MEM NPs. [B] Comparable Brn3a labelled retinal flat mounts from contralateral eyes (top), OHT eyes treated with MEMNPs (middle) and OHT only group (bottom). [C] Whole retinal RGC density measurements indicate that while OHT induction caused a significant reduction in RGC density, RGC loss was mitigated by twice-daily administration of MEM-NPs (one-way ANOVA with Tukey post hoc 


\section{WILEY-VCH}

test, $* * * p<0.0001)$. Values are expressed as mean \pm SE. Naïve and OHT only Brn-3a whole retinal counts from DA rats was obtained from our previous work ${ }^{[34]}$. 